\title{
EXTRASYSTOLES ARISING FROM THE MAIN BUNDLE OF HIS
}

\author{
BY \\ EVAN FLETCHER
}

\author{
From the Belfast City Hospital
}

Extrasystoles arising from a homogenetic focus in the main bundle of His are very rare. Lewis (1911) and Lewis and Allen (1913) each published a single case, and laid down the criteria for the cardiographic diagnosis. They stressed the importance of the marked similarity of the ectopic beats to the ventricular complexes of the sinu-auricular beats. The $P$ waves related in time to the ectopic beats may immediately precede their ventricular complexes with a shortened $\mathbf{P}-\mathbf{R}$ interval, or more often, they follow their ventricular complexes and are seen between the QRS and T waves of the ectopic beats. There is no disturbance of the sequence of the $P$ waves by the extrasystoles. Holzmann (1951) published an example of this rare rhythm in which some of the ectopic beats were interpolated. Scherf and Boyd (1950) have recorded a unique case of ventricular parasystole in which the independent automatic centre of impulse formation was situated in the main bundle. Another example is the case of Scherf and Schott (1953), but this record is complicated by intraventricular block.

\section{Case History}

A man, aged 22 years, was referred to hospital on account of irregularity of the heart beat. He had no cardiac symptoms, and on clinical examination there was no abnormality of the heart apart from the extrasystolic arrhythmia. Serial cardiograms confirmed that the $\mathbf{P}$ waves in all leads related in time to the ectopic beats resembled the $\mathbf{P}$ waves of the supra-ventricular beats. Cuttings from lead II are shown in Fig. 1.

\section{Cardiographic Analysis}

The ectopic beats in A, B, and C closely resemble the ventricular complexes of the sinu-auricular beats. Their $\mathbf{R}$ waves are slightly higher, but this minor degree of aberration is much less than in the case described by Lewis and Allen (1913), and does not invalidate the placing of the ectopic centre above the bifurcation. Moreover, the intra-ventricular conduction time of the ectopic beats is the same as that of the normal beats $(0.07 \mathrm{sec}$.$) . As the T$ waves are isoelectric, the similarity of the $P$ waves related in time to the ectopic beats to the $P$ waves of the sinu-auricular beats is made more obvious. The second $P$ wave of $B$, and the fifth $\mathbf{P}$ wave of $\mathbf{C}$ are slightly distorted by the positive $\mathbf{T}$ waves of the extrasystolic beats. The second $\mathbf{P}$ wave of $C$ precedes the QRS of the extrasystole with a shortened P-R interval. This is similar to Fig. 1 of Lewis' case (1911). When the P wave following an extrasystole is blocked, the post-extrasystolic interval is compensatory (sixth $\mathbf{P}$ wave of $\mathbf{A}$ and second $\mathbf{P}$ wave of $\mathbf{C}$ ). The auricular cycle lengths of $\mathbf{A}$ and $\mathbf{B}$ are $0.98,0.94,0.92,0.90,0.90,0.96,0.92,0.92,0.92,0.96 \mathrm{sec}$, the range of variation being small, within $0.08 \mathrm{sec}$. The auricular cycle lengths of $C$ are $0.76,0.78,0.84,0.96,0.92 \mathrm{sec}$., the range of variation being 0.2 sec., i.e. greater than $A$ and $B$. The auricular cycle lengths of $D$ are 1.12, 1.20, 1.06, 1.24 sec. The extrasystoles in D are more aberrant than in A, B, and C, but they are produced here as close inspection of their ventricular complexes shows evidence of small superimposed negative $P$ waves indicating retrograde auricular activation by the ectopic beats.

In addition to the extrasystoles, there is first degree A-V block (P-R $0.22-0.26 \mathrm{sec}$.), the delay in A-V conduction being greater in the post-extrasystolic beats (P-R 0.25-0.28 sec.), due to fatigue of the conducting pathways by the two preceding ventricular beats occurring close together. The $T$ waves of the postextrasystolic beats are more negative than those of the other supra-ventricular beats. 


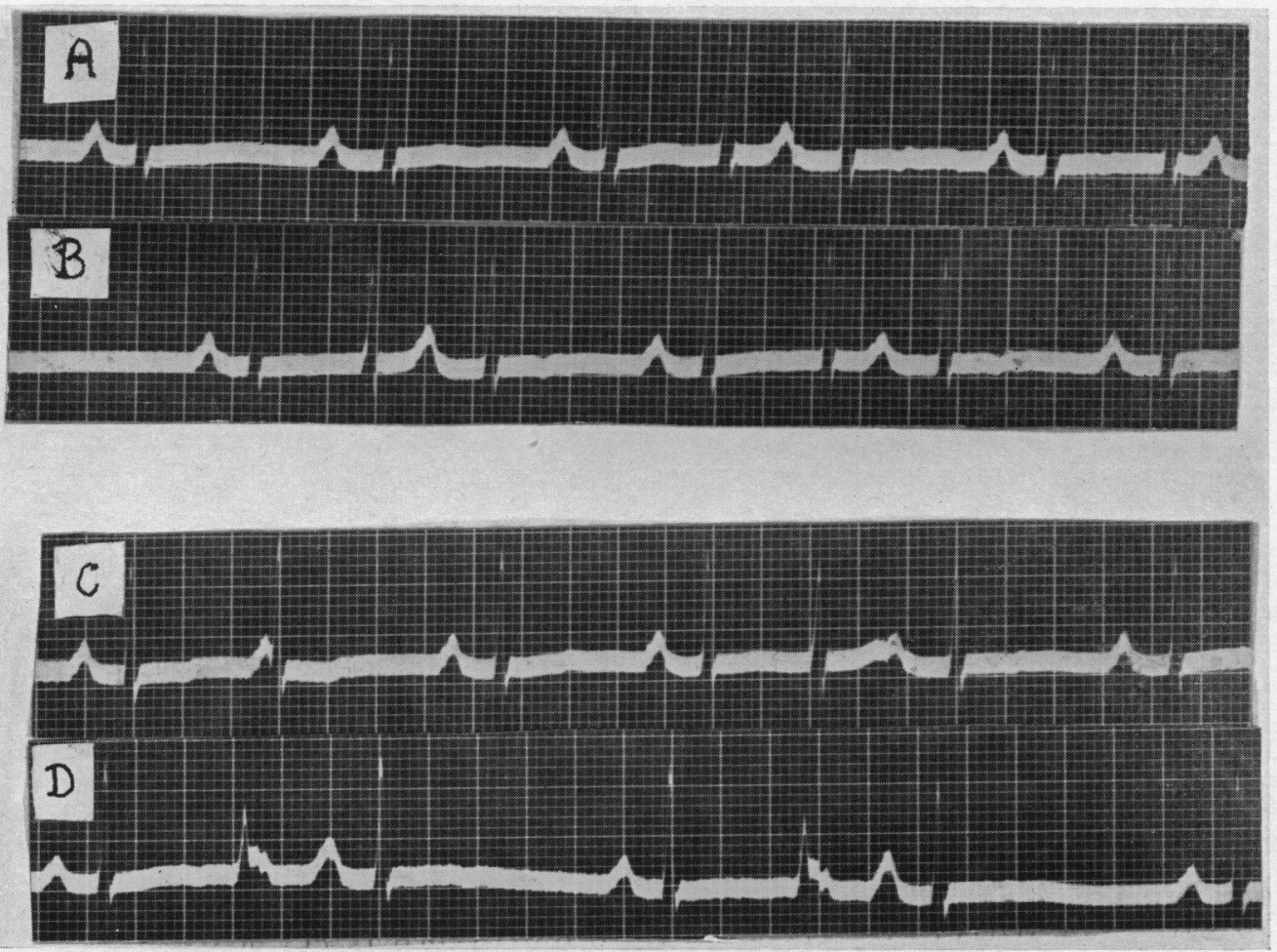

FIG. 1.-Extrasystoles arising from main bundle of His. Lead II. A and B are continuous records, C and $\mathrm{D}$ are separate. Time markings: $0.04 \mathrm{sec}$.

\section{Discussion}

The fact that the extrasystoles are interpolated confirms that their focus of origin is in the ventricles, for interpolated auricular extrasystoles have not been conclusively proven to occur in the human heart (Scherf and Schott, 1953). The essentially normal pattern of ventricular activation during the propagation of the ectopic beats indicates that their site of origin is above the bifurcation of the main bundle of His, either in the main stem or in the A-V node. Since nodal extrasystoles activate the auricles in a retrograde fashion, the excitation wave discharges the sinus pacemaker, thereby causing a shift of the dominant rhythm. There is no shift of the sinus pace maker in this case by any such mechanism, even though $\mathrm{D}$ shows evidence of retrograde conduction of the ectopic beats along the conducting pathways in the auricles. Presumably therefore the ectopic centre is situated in the main bundle rather than in the A-V node itself. Alternatively, it could be assumed that the ectopic centre is in the A-V node, and that the sinus pace maker is protectively blocked against A-V impulses. Such blocked nodal extrasystoles, as in Wenckebach and Winterberg's case (1927), could not be differentiated from main stem extrasystoles. There is no evidence in A and $B$ that the time sequence of the $P$ waves is influenced by the ectopic beats, the narrow range of variation of the auricular cycle lengths noted above being presumably spontaneous. In $\mathrm{D}$, however, the auricular cycle length immediately following each extrasystole is longer than the immediately preceding auricular cycle length. The explanation appears to be that the double auricular activation by the retrograde conduction of the ectopic beat and the rapidly succeeding sinus beat, leads to fatigue of the conducting pathways in the auricles, so that when the next sinus beat occurs, activation of the auricles is slightly delayed and the auricular cycle length is thereby prolonged. It is apparent therefore that if extrasystoles arising in the main bundle are conducted backwards to 
the auricles, they may influence the sinus rhythm even though they do not discharge the sinus pace maker. In such a case, the strict criteria laid down by Lewis (1911) and Lewis and Allen (1913) for the diagnosis of stem extrasystoles, concerning the " absence of disturbance of the sequence of the $P$ waves," may require revision.

\section{Summary}

A case of extrasystolic arrhythmia is analysed, in which the ectopic centre appears to be situated above the bifurcation of the main bundle of His. The difficulty of locating the focus, either in the main stem or A-V node, is discussed. Attention is drawn to the possible effect of retrograde conduction on the sequence of the sinu-auricular beats, apart from discharge of the sinus node, with particular reference to auricular fatigue. The great rarity of this disturbance of rhythm is noted, and reference made to the few previously reported instances.

I wish to acknowledge the helpful advice of Dr. David Scherf, New York Medical College.

\section{References}

Holzmann, M. (1952). Clinical Electrocardiography. English translation (A. Staples), page 454. Lewis, T. (1911). Quart. J. Med., 5, 1.

- and Allen, H. W. (1913). Amer. J. med. Sci., 145, 667.

Scherf, D., and Boyd, L. J. (1950). Amer. Heart J., 39, 650 .

- and Schott, A. (1953). Extrasystoles and Allied Arrhythmias. Page 96, Fig. 71. Heinemann.

Wenckebach, K. F., and Winterberg, H. (1927). Die unregelmässige Herztätigkeit. Fig. 138, Plate 57. Engelmann, Leipzig. 